\title{
Sistem Pendukung Keputusan Monitoring dan Peramalan Harga Beras di Kabupaten Deli Serdang, Sumatera Utara
}

\author{
Decision Support System for Monitoring and Forecasting of Rice Price in Deli Serdang, North Sumatera
}

\author{
Ferlando Jubelito Simanungkalit*, Benika Naibaho \\ Fakultas Pertanian, Universitas HKBP Nommensen \\ Jl. Sutomo No. 4A Medan, Sumatera Utara 20234, Indonesia \\ Email: ferlandoskalit@yahoo.com
}

Tanggal submisi: 29 November 2016; Tanggal penerimaan: 30 April 2018

\begin{abstract}
ABSTRAK
Sistem pendukung keputusan monitoring dan peramalan harga beras dirancang untuk memberikan prediksi harga masa depan dan dukungan keputusan bagi para pembuat kebijakan dalam melakukan stabilisasi harga beras. Tujuan penelitian ini adalah merancang prototipe Sistem Pendukung Keputusan (SPK) dengan terlebih dahulu menganalisis arsitektur Jaringan Saraf Tiruan (JST) yang paling sesuai untuk digunakan sebagai metode peramalan/subsistem model SPK. Kajian dilakukan dengan menggunakan data harga bulanan komoditas beras IR64 di Kabupaten Deli Serdang, Sumatera Utara bulan Januari 2000-Desember 2015. Arsitektur model JST terbaik dipilih berdasarkan pada nilai Mean Square Error (MSE) dan Mean Absolute Percentage Error (MAPE) terkecil dari hasil pelatihan, pengujian dan validasi. Arsitektur model JST terbaik kemudian dirancang menjadi subsistem model SPK bersamaan dengan basis data, komponen pengetahuan dan tampilan antarmuka menggunakan fase-fase perancangan sistem pendukung keputusan. SPK dirancang untuk digunakan berbasis web (web base) agar memudahkan interaksi dengan pengguna (user) dan arus pertukaran data. SPK diprogram menggunakan bahasa pemrograman PHP. Dari 73 percobaan analisis arsitektur model JST yang telah dilakukan, diperoleh satu arsitektur JST dengan performa peramalan terbaik yang digunakan sebagai metode peramalan dengan arsitektur 12-1-1, fungsi aktivasi purelin pada lapisan tersembunyi, fungsi aktivasi purelin pada lapisan output, algoritma pelatihan traingda (gradient descent with adaptive learning rate) dan nilai laju pembelajaran 0,1 . Nilai MSE dan MAPE dari hasil pelatihan, pengujian dan validasi berturut-turut adalah 0,00128 dan 3,57\%; 0,0319 dan 5,47\%; 0,0052 dan 2,51\%. Hasil validasi menunjukkan bahwa hasil peramalan yang dihasilkan oleh SPK memiliki tingkat akurasi $90 \%$.
\end{abstract}

Kata kunci: Jaringan saraf tiruan; sistem pendukung keputusan; peramalan harga; beras

\begin{abstract}
The goal of this research was to design a Decision Support System (DSS) to monitor and forecast the price of rice. This system was designed to help the policy makers in decision making process to stabilize the rice price. The most fitted model base of the DSS forecasting method was selected by analyzing the architecture of Artificial Neural Network (ANN). The best fitted ANN architecture was selected based on the smallest value of Mean Square Error (MSE) and Mean Absolute Percentage Error (MAPE) in training, testing, and validation. The research was done using the monthly price of rice IR64 in District Deli Serdang, North Sumatera from January 2000 to December 2015. Decision support system developing phases was used to create the best match of ANN architecture for the model base of the DSS along with the database, the knowledge base, as well as the user interface. DSS was programmed using the PHP programming and was designed in a web base to facilitate the interaction between the DSS, the system's users, and the flow of data exchange. From 73 trials unit of the ANN architecture analysis, it has been obtained that an ANN 12$1-1$, purelin activation function inside the hidden layer, purelin activation function inside the output layer, traingda training algorithm (gradient descent with adaptive learning rate) and the value of learning rate was 0,1 were the best match for developing the DSS forecasting method. Furthermore, the MSE and MAPE of the training, testing and validation in a row were 0.00128 and $3.57 \% ; 0.0319$ and $5.47 \% ; 0.0052$ and $2.51 \%$. The validation results showed that the forecasting results that has been produced by the DSS has a $90 \%$ accuracy.
\end{abstract}

Keywords: Artificial neural networks; decision support systems; price forecasting; rice 


\section{PENDAHULUAN}

Beras merupakan sumber karbohidrat utama yang harus ada dalam pola makanan masyarakat Indonesia sehari-hari. Mengkonsumsi beras sudah menjadi bagian tidak terpisahkan dari budaya pangan masyarakat Indonesia. Oleh sebab itu, Indonesia menjadi salah satu negara pengkonsumsi beras paling besar di dunia. Karena kebutuhan beras yang tinggi dan ketidakmampuan Indonesia dalam mencapai swasembada beras, Indonesia juga merupakan negara pengimpor beras terbesar di dunia. Sebagai komoditas pangan utama, permasalahan beras bukan hanya merupakan permasalahan ekonomi, tetapi juga bersifat politis (Sa'id dkk. 2007).

Masalah utama dalam perberasan nasional adalah masalah harga dan non harga beras. Masalah yang paling kontroversial sehubungan dengan masalah harga beras adalah fluktuasi harga beras (Nainggolan, 2007). Harga beras seringkali menjadi masalah kontroversial menyangkut kepentingan petani dan kepentingan masyarakat konsumen beras. Pada sisi pertama, pemerintah sebagai regulator berusaha menjaga kepentingan petani dan berusaha mewujudkan kesejahteraan yang optimal bagi petani, tetapi di sisi berikutnya pemerintah juga ingin memberikan perlindungan agar harga beras dapat dijangkau oleh masyarakat, bahkan dapat dijangkau oleh petani yang pada waktu tertentu harus menjadi pembeli beras.

Dari berbagai aspek ekonomi pangan, harga merupakan salah satu indikator penting yang perlu terus diperhatikan. Pentingnya persoalan harga pangan terutama di tingkat petani-produsen (dengan tetap melindungi konsumen), dilakukan oleh pemerintah di berbagai negara melalui kebijakan intervensi pasar. Secara umum tujuan kebijakan pemerintah terkait harga pangan adalah untuk mencapai salah satu atau kombinasi dari beberapa hal berikut: (1) mendorong peningkatan penghasilan petani, (2) memproteksi petani kecil agar tetap memiliki insentif dalam menghasilkan pangan, (3) mencapai swasembada pangan dan mengurangi ketergantungan impor pangan, (4) menjaga stabilitas harga dan pendapatan petani, (5) meningkatkan daya beli konsumen untuk memenuhi kebutuhan pangan (Rachman, 2005).

Salah satu usaha yang dapat dilakukan untuk mengantisipasi terjadinya fluktuasi harga adalah dengan melakukan peramalan harga. Peramalan harga ditujukan untuk melakukan prakiraan/peramalan harga dalam kurun waktu tertentu. Hasil peralaman harga adalah harga masa depan. Peramalan harga difokuskan untuk memperoleh gambaran mengenai keadaan di masa yang akan datang, sehingga dapat digunakan dalam proses pengambilan keputusan terkait guna meminimalisasi resiko dan memaksimalkan potensi keuntungan yang dapat diraih (Leal dan Melin 2007).

Peramalan harga-harga komoditas pertanian sangat berguna bagi para petani, pemerintah dan industri pertanian. Oleh karena itu, kemampuan untuk meramalkan harga komoditas pertanian dengan tepat adalah urusan yang sangat penting dalam hal kebijakan dan bisnis (Jha dan Sinha 2014).

Peramalan merupakan proses pendugaan keadaan pada masa yang akan datang. Kebutuhan akan peramalan diakibatkan oleh karena adanya jeda waktu (time lag) antara suatu hal atau peristiwa dengan kebutuhan mendatang. Peramalan adalah prakiraan/estimasi dari nilai masa depan suatu variabel berdasarkan pada sifat/perilaku masa lalu dari suatu deret waktu (Leal \& Melin, 2007). Khin dkk. (2008) menyatakan bahwa dalam kondisi yang sangat tidak pasti dan beresiko tinggi, peramalan-peramalan harga sangat diperlukan untuk membantu pengambilan keputusan.

Sistem Pendukung Keputusan (SPK) adalah suatu sistem atau subsistem interaktif berbasis komputer yang ditujukan untuk membantu para pembuat keputusan. SPK dirancang menggunakan teknologi komunikasi, data, dokumen, pengetahuan dan/atau model untuk mengindentifikasi dan memecahkan masalah, menyelesaikan proses pengambilan keputusan dan membuat keputusan-keputusan (Karmakar dkk. 2007).

SPK berbasis pertanian adalah aplikasi perangkat lunak berbasis pada model-model komputer yang menggambarkan berbagai proses biofisika dalam sistem pertanian dan respon terhadap praktek-praktek pengelolaan pertanian. Seperti irigasi, pemupukan, penaburan benih dan tanggal pemanenan dan/atau variabilitas iklim seperti temperatur dan curah hujan (Jakku dan Thorburn 2010).

Jaringan saraf tiruan memiliki performa peramalan yang baik saat digunakan sebagai metode dalam memprediksi harga (Pao, 2007); (Hamzaçebi, 2008); (Li dkk. 2010); (Singhal dan Swarup 2011); (Li dkk. 2013); (Laboissiere dkk. 2015); (Panapakidis dan Dagoumas 2016).

Efendigil dkk. (2009) merancang sistem pendukung keputusan untuk memprediksi permintaan pasar menggunakan model jaringan saraf tiruan. Pavan dkk. (2011) merancang sistem pendukung keputusan berbasis web untuk memprediksi penyakit stroberi. Candea dkk. (2012) mengemukakan kerangka perancangan sistem pendukung keputusan berbasis web.

Surjasa dkk. (2011) merancang model sistem prakiraan dan peringatan dini pasokan dan harga beras di Propinsi DKI Jakarta menggunakan jaringan saraf tiruan. Adapun tingkat akurasi peramalan pasokan beras dan harga beras melebihi $90 \%$.

Simanungkalit dkk. (2013) mengembangkan SPK berbasis jaringan saraf tiruan untuk peramalan harga komoditas tanaman pangan. SPK yang dikembangkan terdiri dari komponen subsistem proses, subsistem basis data, subsistem komponen pengatahuan dan subsistem tampilan antarmuka. Subsistem SPK dari hasil penelitian ini dapat digunakan untuk memprediksi harga komoditas beras IR64, gabah padi IR64, jagung kuning pipilan, kacang tanah, ketela pohon dan ketela rambat di 
Kabupaten Sleman, Yogyakarta. Adapun model JST yang digunakan sebagai model base SPK untuk memprediksi harga beras IR64 memiliki tingkat akurasi $96 \%$.

Tujuan penelitian ini adalah pengembangan Sistem Pendukung Keputusan (SPK) berbasis Jaringan Saraf Tiruan (JST) yang dapat dipergunakan sebagai instrumen untuk memprediksi harga beras masa depan. Perancangan subsistem proses (model base) SPK dilakukan dengan menganalisis arsitektur JST yang paling tepat untuk digunakan sebagai metode peramalan. Hasil peramalan yang dihasilkan oleh subsistem proses SPK selanjutnya dapat digunakan dan diproses kembali oleh subsistem komponen pengetahuan (knowledge base) SPK menjadi informasi peringatan dini (early warning system), yang kemudian dapat dipergunakan sebagai pedoman dalam proses pengambilan keputusan penstabilan harga beras.

\section{METODE PENELITIAN}

Tahapan pelaksanaan penelitian rancang bangun Sistem Pendukung Keputusan Monitoring dan Peramalan Harga Beras dilakukan mengikuti tahapan fase-fase pembangunan SPK yang dikembangkan oleh Turban (1993) seperti pada Gambar 1. Adapun fase-fase tersebut terdiri atas 8 fase.

\section{Fase A: Perencanaan}

Dalam fase perencanaan ada dua hal yang harus diselesaikan, yaitu penentuan kebutuhan dan penentuan sasaran SPK. Berdasarkan pada hasil perencanaan, terdapat 3 kebutuhan yang harus diselesaikan dengan membangun SPK, yaitu (1) kebutuhan akan sistem monitoring harga beras yang dapat menyimpan dan mengelola data harga beras di dalam basis data; (2) kebutuhan akan sistem peramalan harga beras yang dapat memprediksi harga beras secara tepat dan akurat; (3) kebutuhan akan sistem yang dapat menganalisa hasil peramalan yang telah dilakukan dan mampu memberikan dukungan keputusan yang harus dilakukan sebagai tindakan antisipatif terhadap hasil peramalan harga masa depan. Dalam fase perencanaan juga ditentukan sasaran yang akan menggunakan SPK, yaitu para pengambil kebijakan (dalam hal ini pemerintah) sebagai regulator yang selalu melakukan stabilisasi harga beras dan memantau pasokan beras di pasar.

\section{Fase B: Penelitian}

Fase penelitian dilakukan dengan cara mengumpulkan data dan informasi yang diperlukan untuk membangun SPK. Kajian analisis model peramalan dilakukan dengan mengumpulkan data harga beras IR64 tingkat bulanan dari Januari 2000-Desember 2015 yang diperoleh dari Biro Pusat Statistik Kabupaten Deli Serdang, Sumatera Utara. Fase penelitian juga memberikan kuesioner isian kepada calon pengguna SPK, yang terdiri dari Dinas Pertanian Kab. Deli Serdang, Dinas Perdagangan Kab.
Deli Serdang, Bulog Kab. Deli Serdang, dan Bulog Divre Sumatera Utara sebagai regulator yang memantau harga dan pasokan beras di pasar. Pengisian kuesioner dimaksudkan untuk mendapatkan data dan informasi yang diperlukan oleh para pengguna dalam proses monitoring dan peramalan harga beras. Kuesioner juga ditujukan untuk mendapatkan kebijakan-kebijakan yang biasa dilakukan oleh para pengguna sistem dalam menyikapi hasil peramalan harga dan tampilan yang dibutuhkan oleh pengguna dalam menggunakan sistem. Fase penelitian adalah dasar dari penentuan rancangan subsistem proses, subsistem basis data, subsistem pengetahuan dan subsistem tampilan antarmuka.

\section{Fase C: Analisis}

Fase analisis bertujuan untuk menganalisa seluruh data dan informasi yang diperoleh dari fase penelitian. Data-data harga beras yang diperoleh dari Biro Pusat Statistik Kabupaten Deli Serdang digunakan di dalam analisis arsitektur JST untuk mendapatkan model peramalan harga beras yang tepat dan akurat. Dalam fase analisis terdapat 73 percobaan arsitektur JST yang dianalisa melalui proses pelatihan, pengujian dan validasi seperti yang ditampilkan pada Tabel 1 . Pemilihan arsitektur model JST terbaik ditentukan dari nilai Mean Square Error (MSE) dan Mean Absolute Percentage Error (MAPE) terkecil dari hasil pelatihan, pengujian dan validasi. Arsitektur JST yang digunakan terdiri dari 12 unit neuron pada lapisan input, 1 unit neuron pada lapisan output dan jumlah neuron di dalam lapisan tersembunyi divariasikan sesuai dengan parameter percobaan.

Tabel 1. Parameter percobaan analisis arsitektur JST peramalan harga beras

\begin{tabular}{|c|c|c|c|c|}
\hline $\begin{array}{c}\text { Jumlah } \\
\text { neuron } \\
\text { dalam } \\
\text { lapisan } \\
\text { tersembun } \\
\text { yi }\end{array}$ & $\begin{array}{c}\text { Fungsi } \\
\text { aktivasi } \\
\text { lapisan } \\
\text { tersembun } \\
\text { yi }\end{array}$ & $\begin{array}{l}\text { Fungsi } \\
\text { aktiva } \\
\text { si } \\
\text { lapisa } \\
\text { n } \\
\text { ouput }\end{array}$ & $\begin{array}{c}\text { Algoritma } \\
\text { pembelajara } \\
n\end{array}$ & $\begin{array}{c}\text { Laju } \\
\text { pembelajara } \\
\text { n (learning } \\
\text { rate) }\end{array}$ \\
\hline $\begin{array}{l}1 \text { unit } \\
25 \text { unit } \\
37 \text { unit } \\
49 \text { unit } \\
61 \text { unit }\end{array}$ & $\begin{array}{l}\text { Logsig } \\
\text { Tansig } \\
\text { Purelin }\end{array}$ & $\begin{array}{l}\text { Logsig } \\
\text { Tansig } \\
\text { Purelin }\end{array}$ & $\begin{array}{c}\text { Traingdx } \\
\text { Traingd } \\
\text { Traingda } \\
\text { Traingdm } \\
\text { Trainbfg } \\
\text { Trainrp } \\
\text { Trainlm }\end{array}$ & $\begin{array}{c}0,1 \\
0,01 \\
0,001 \\
0,0001\end{array}$ \\
\hline 5 & 3 & 3 & 7 & 4 \\
\hline Total pe & obaan & \multicolumn{2}{|c|}{$\begin{array}{c}(5 \times 3 \times 3)+(7 \times 4) \\
=45+28\end{array}$} & 73 \\
\hline
\end{tabular}

Percobaan analisis arsitektur JST dilakukan dengan menggunakan data harga beras IR64 tingkat bulanan sejak Januari 2000 hingga Desember 2015, dan 
dicobakan menggunakan bahasa pemrograman Matlab R2010a. Data yang akan digunakan sebagai input JST dipersiapkan terlebih dahulu dengan cara dibagi menjadi data pelatihan, data pengujian dan data validasi. Data pelatihan digunakan sebagai input dalam proses pelatihan JST, sedangkan data pengujian digunakan sebagai input dalam proses pengujian JST yang telah selesai dilatih, dan data validasi digunakan sebagai input dalam proses validasi JST peramalan harga beras terbaik. Porsi data yang dipakai dalam proses pelatihan, pengujian dan validasi berturut-turut adalah $73 \%$, 20\%, dan $7 \%$.

\section{Fase D: Perancangan}

Fase perancangan dilakukan untuk membentuk masing-masing komponen subsistem penyusun SPK, terdiri dari perancangan subsistem proses, perancangan basis data, perancangan subsistem komponen pengetahuan dan perancangan subsistem tampilan antarmuka.

Perancangan subsistem proses dilakukan dengan memasukkan bobot-bobot akhir dari arsitektur JST dengan performa peramalan terbaik ke dalam algoritma peramalan. Perancangan subsistem proses dilakukan dengan menggunakan bahasa pemrograman PHP. Perancangan basis data dilakukan dengan menggunakan sistem basis data relasional MySQL untuk mempermudah pertukaran data dan pengelolaan manajemen data di dalam sistem. Masing-masing tabel basis data mempunyai kode karakter khusus untuk memudahkan pemanggilan basis data di dalam sistem. Perancangan subsistem pengetahuan dilakukan dengan menyusun algoritma dukungan keputusan berdasarkan pada matriks keputusan yang diperoleh dari hasil tabulasi kuesioner yang diberikan kepada calon pengguna (user) SPK. Perancangan subsistem komponen pengetahuan dilakukan dengan menggunakan bahasa pemrograman PHP. Perancangan subsistem tampilan antarmuka dilakukan dengan menggunakan informasi dari hasil tabulasi kuesioner yang diberikan kepada calon pengguna (user) SPK. Perancangan subsistem tampilan antarmuka mengacu kepada prinsip ramah penggunaan (user friendly) agar memudahkan para pengguna yang minim pengetahuan komputer dalam menggunakan SPK. Perancangan subsistem tampilan antarmuka dilakukan dengan menggunakan bahasa pemrograman PHP.

\section{Fase E: Penggabungan}

Fase penggabungan ditujukan untuk menyatukan subsistem-subsistem SPK yang telah selesai dirancang menjadi satu kesatuan utuh yang tidak terpisahkan. Penggabungan seluruh subsistem SPK menjadi Sistem Pendukung Keputusan Monitoring dan Peramalan Harga Beras dilakukan dengan menggunakan bahasa pemrograman PHP.

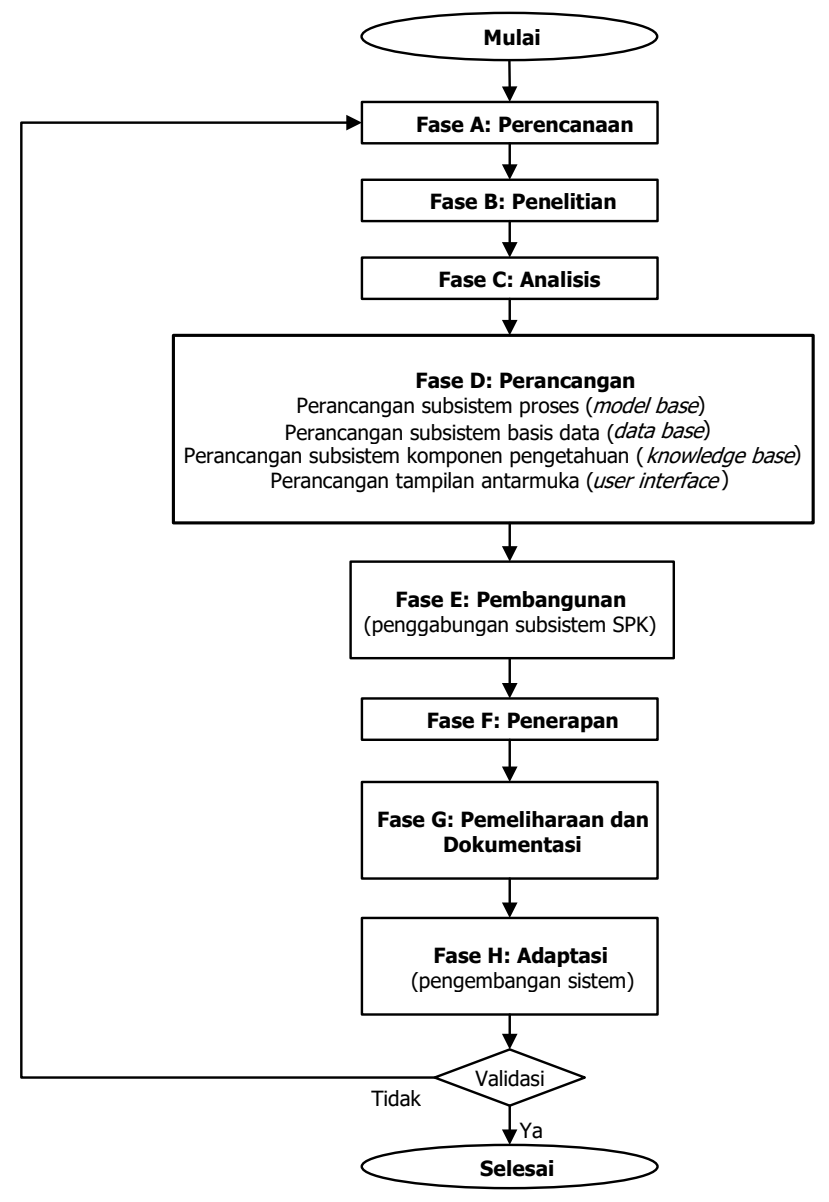

Gambar 1. Diagram alir penelitian: fase-fase pembangunan sistem pendukung keputusan (Turban, 1993).

\section{Fase F: Penerapan}

Fase penerapan dilakukan dengan menguji-cobakan Sistem Pendukung Keputusan Monitoring dan Peramalan Harga Beras untuk menjalankan fungsi-fungsinya. Dalam fase ini seluruh fitur-fitur yang dimiliki oleh SPK diuji-coba, apakah berjalan dengan baik sesuai fungsinya? Apabila seluruh fitur SPK berfungsi dengan baik dan program dapat berjalan sesuai dengan algoritma pemrograman yang telah ditentukan, maka SPK dapat diproses ke tahap selanjutnya. Tetapi apabila ada fitur-fitur dan fungsi SPK yang tidak dapat berjalan sesuai dengan perancangannya, maka SPK masuk kembali ke tahapan perancangan dan penggabungan untuk kemudian diperbaiki.

\section{Fase G: Pemeliharaan dan Dokumentasi}

Fase pemeliharaan dan dokumentasi ditujukan untuk memelihara fungsi-fungsi dan fitur-fitur yang dimiliki oleh SPK dapat berjalan dengan baik. Fase pemeliharaan dan dokumentasi dilakukan dengan mengupdate basis data dan informasi-informasi yang ditampilkan di dalam SPK, sehingga membuat basis data dan informasi yang dimiliki oleh SPK tidak ketinggalan jaman. 


\section{Fase H: Adaptasi}

Fase adaptasi ditujukan untuk mengembangkan fungsi-fungsi dan fitur-fitur yang dimiliki oleh SPK. Pengembangan SPK ditujukan untuk meningkatkan kemampuan yang dimiliki oleh SPK, sehingga SPK memiliki kemampuan yang lebih baik dalam memberikan dukungan keputusan.

\section{HASIL DAN PEMBAHASAN}

\section{Perancangan Subsistem Proses (Model Base)}

Arsitektur JST yang digunakan sebagai metode untuk melakukan peramalan harga beras adalah jaringan saraf tiruan dengan banyak lapisan atau Multi Layer Feedforward Network (MLFN) dengan algoritma pembelajaran backpropagation. Tujuan penggunaan arsitektur JST dengan banyak lapisan sebagai model peramalan harga beras adalah karena kemampuannya yang cukup baik dalam menyelesaikan masalah-masalah yang rumit. Penggunaan algoritma pembelajaran backpropagation ditujukan karena kemampuan algoritma ini untuk merambatkan kembali error yang dihasilkan pada lapisan output selama proses pelatihan JST kembali ke lapisan input, untuk kemudian dilatih kembali guna meminimalkan error (tingkat kesalahan) yang dihasilkan oleh JST.

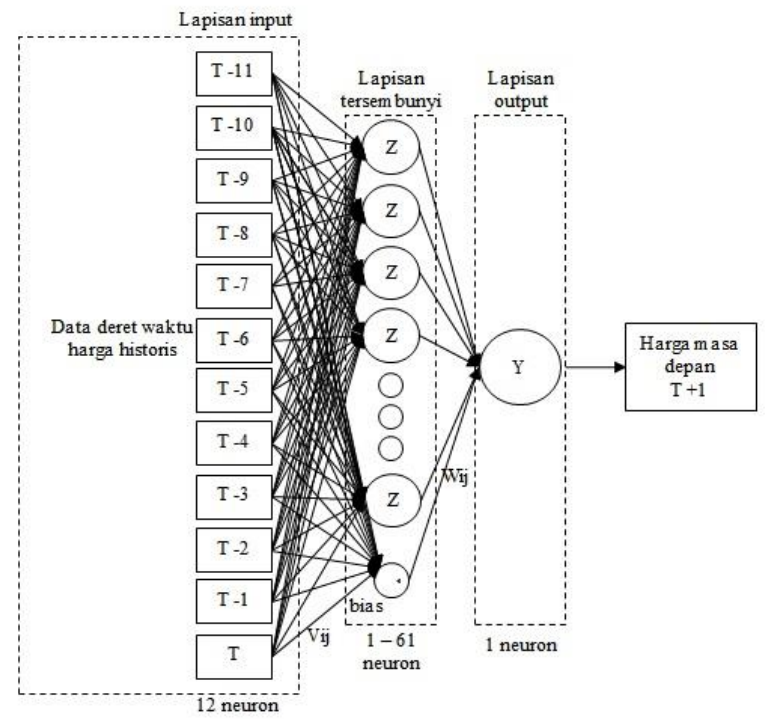

Gambar 2. Arsitektur model JST peramalan harga beras terbaik

Arsitektur JST yang digunakan dalam penelitian ini terdiri dari 3 lapisan yaitu: lapisan input (input layer), lapisan tersembunyi (hidden layer) dan lapisan output (output layer) seperti tampilan pada Gambar 2. Penggunaan jumlah 12 neuron di dalam lapisan input JST didasarkan atas satu siklus waktu tahunan (1 tahun terdiri dari 12 bulan), sehingga arsitektur JST ini menggunakan data harga beras saat ini $(\mathrm{T})$ dan data harga beras 11 periode sebelumnya ( $T_{-1}$ sampai dengan $T_{-11}$ ) untuk meramalkan harga beras satu periode waktu ke depan $\left(T_{+1}\right)$.

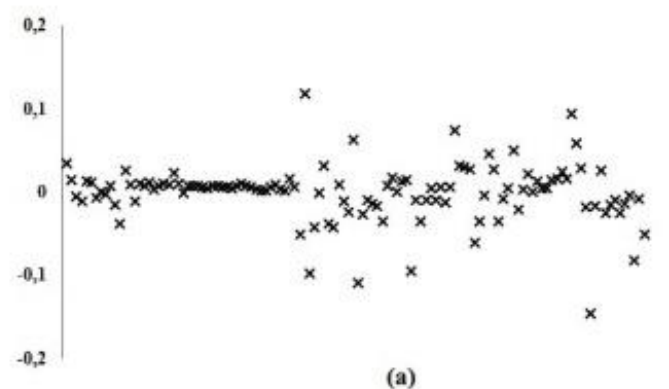

(a)

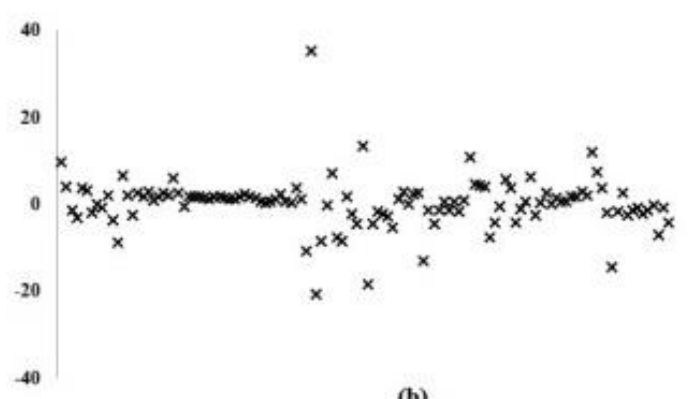

(b)

Gambar 3. Plot error pelatihan (a) dan persentase error pelatihan (b) model JST peramalan harga beras terbaik

Dari 73 percobaan arsitektur JST yang dilakukan, diperoleh satu arsitektur JST peramalan harga beras terbaik yaitu JST dengan arsitektur $12-1-1$ dengan fungsi aktivasi purelin pada lapisan tersembunyi, fungsi aktivasi purelin pada lapisan output, algoritma pelatihan traingda (gradient descent and an adaptive learning rate) dan nilai laju pembelajaran 0,1 .
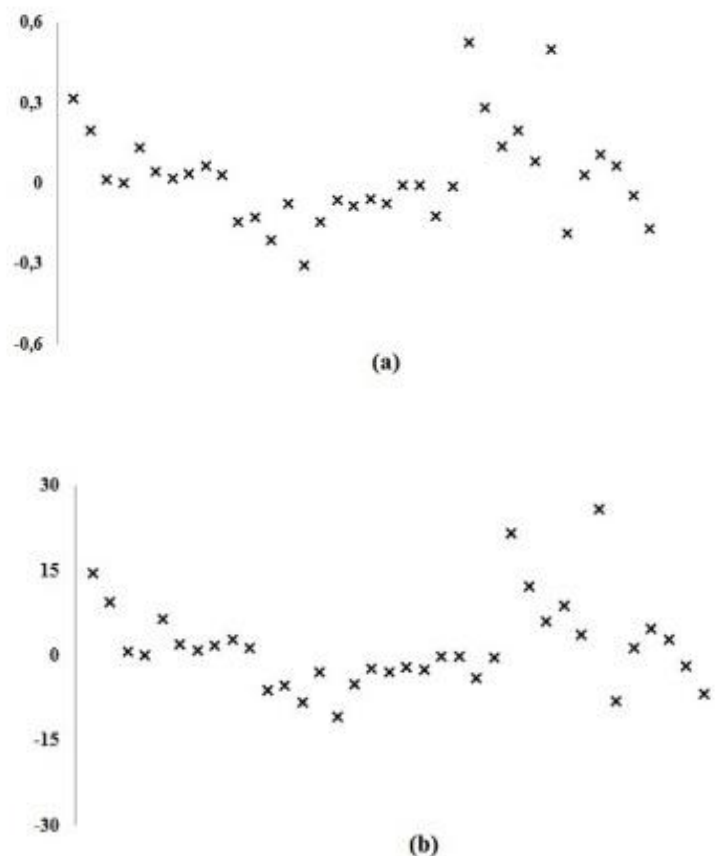

Gambar 4. Plot error pengujian (a) dan persentase error pengujian (b) model JST peramalan harga beras terbaik 


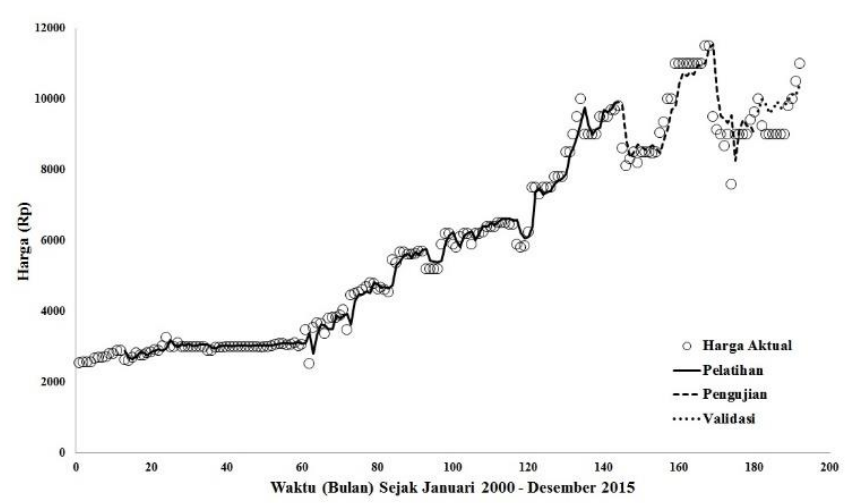

Gambar 5. Simulasi output hasil pelatihan dan pengujian model JST peramalan harga beras terbaik dengan harga beras aktual Januari 2001 sampai Desember 2014

Performa hasil pelatihan model JST peramalan harga beras terbaik adalah MSE $=0,00128 ; \mathrm{R}=0,9922$; dan MAPE $=3,57 \%$. Adapun nilai error dari hasil pelatihan model JST peramalan harga beras terbaik, tersaji seperti grafik pada Gambar 3.

Performa hasil pengujian model JST peramalan harga beras terbaik adalah MSE $=0,0319 ; \quad R=0,7859$ dan MAPE $=5,47 \%$. Adapun nilai error dari hasil pengujian model JST peramalan harga beras terbaik, tersaji seperti grafik pada Gambar 4.

Proses validasi model JST peramalan harga beras terbaik dilakukan dengan membandingkan hasil peramalan JST selama 12 bulan ke depan (meramal harga beras selama tahun 2015) dengan data harga beras aktual selama tahun 2015. Adapun hasil validasi model JST peramalan beras terbaik dapat dilihat pada Tabel 2 .

Berdasarkan hasil validasi dapat dilihat bahwa model JST peramalan harga beras terbaik dapat melakukan peramalan harga beras dengan baik dan dapat mengikuti pola harga beras aktual seperti terlihat pada Gambar 5 . Adapun persentase kesalahan peramalan yang tertinggi terjadi pada peramalan harga beras bulan Januari 2015 dengan nilai persentase kesalahan peramalan - 6,19\%; sedangkan kesalahan peramalan yang terendah terjadi pada peramalan harga beras bulan Februari 2015 dengan nilai persentase kesalahan peramalan - 0,07\%. Secara keseluruhan, rata-rata nilai persentase kesalahan peramalan dari hasil peramalan selama satu tahun adalah sama dengan nilai MAPE (Mean Absolute Percentage Error) 2,36\%. Persentase kesalahan peramalan yang dihasilkan oleh JST terbaik pada masing-masing satuan peramalan juga tidak melebihi nilai $10 \%$, masih berada pada kisaran kurang dari $10 \%$. Oleh karena itu, toleransi kesalahan peramalan yang dihasilkan oleh model JST peramalan harga beras terbaik adalah $10 \%$, dengan tingkat akurasi peramalan $90 \%$.

Pelatihan JST akan menghasilkan nilai bobot-bobot akhir jaringan. Nilai dari masing-masing bobot jaringan tersebut digunakan untuk merancang algoritma peramalan yang akan digunakan sebagai subsistem proses (model base) SPK. Pembangunan subsistem proses SPK dilakukan dengan menggunakan bahasa pemrograman PHP dengan mengikuti algoritma seperti pada Gambar 6.

\section{Perancangan Subsistem Basis Data (Data Base)}

Perancangan subsistem basis data dilakukan menggunakan sistem basis data relasional MySQL. Perancangan basis data dilakukan dengan membentuk tabel-tabel basis data yang saling berhubungan dan memiliki pengkodean karakter khusus (unique code) untuk memudahkan pemanggilan dan pengelolaan basis data di dalam sistem. Perancangan subsistem basis data dilakukan dengan mempertimbangkan pengembangan SPK di masa depan, menjadi SPK yang mampu melakukan proses monitoring dan peramalan harga beras dengan mencakup wilayah yang lebih luas dan jenis komoditas yang lebih banyak. Oleh sebab itu basis

Tabel 2. Hasil validasi peramalan harga beras aktual dengan hasil peramalan model JST peramalan beras terbaik

\begin{tabular}{|c|c|c|c|c|c|c|c|}
\hline Tahun & Bulan & $\begin{array}{l}\text { Harga aktual } \\
\quad(\mathrm{Rp})\end{array}$ & $\begin{array}{l}\text { Hasil peramalan } \\
\text { JST (Rp) }\end{array}$ & Error JST & $\begin{array}{l}\text { Kuadrat } \\
\text { error JST }\end{array}$ & $\begin{array}{l}\text { Error } \\
(\mathrm{Rp})\end{array}$ & $\begin{array}{c}\text { Persentase error } \\
(\%)\end{array}$ \\
\hline \multirow{13}{*}{2015} & Januari & 10.300 & $9.662,53$ & $-0,1626$ & 0,0264 & -637 & $-6,19$ \\
\hline & Februari & 10.000 & $9.992,77$ & $-0,0018$ & 0,0000 & -7 & $-0,07$ \\
\hline & Maret & 9.700 & $9.864,53$ & 0,0420 & 0,0018 & 165 & 1,70 \\
\hline & April & 10.000 & $9.592,35$ & $-0,1040$ & 0,0108 & -408 & $-4,08$ \\
\hline & Mei & 9.900 & $9.757,04$ & $-0,0365$ & 0,0013 & -143 & $-1,44$ \\
\hline & Juni & 9.600 & $9.929,83$ & 0,0841 & 0,0071 & 330 & 3,44 \\
\hline & Juli & 9.925 & $9.752,09$ & $-0,0441$ & 0,0019 & -173 & $-1,74$ \\
\hline & Agustus & 10.000 & $9.845,81$ & $-0,0393$ & 0,0015 & -154 & $-1,54$ \\
\hline & September & 10.000 & $9.973,10$ & $-0,0069$ & 0,0000 & -27 & $-0,27$ \\
\hline & Oktober & 10.000 & $10.131,46$ & 0,0335 & 0,0011 & 131 & 1,31 \\
\hline & November & 10.500 & $10.098,50$ & $-0,1024$ & 0,0105 & -401 & $-3,82$ \\
\hline & Desember & 10.700 & $10.406,12$ & $-0,0750$ & 0,0056 & -294 & $-2,75$ \\
\hline & & & & MSE & 0,0057 & MAPE & $2,36 \%$ \\
\hline
\end{tabular}


data cakupan wilayah yang terdiri dari provinsi, kabupaten/kota dan komoditas dibuat sebagai tabel basis data tersendiri. Perancangan dengan memperhatikan pengembangan SPK di masa depan akan membuat pengisian dan pengelolaan basis data akan menjadi lebih mudah. Adapun relasi antar tabel di dalam subsistem basis data dapat dilihat seperti pada Gambar 7.

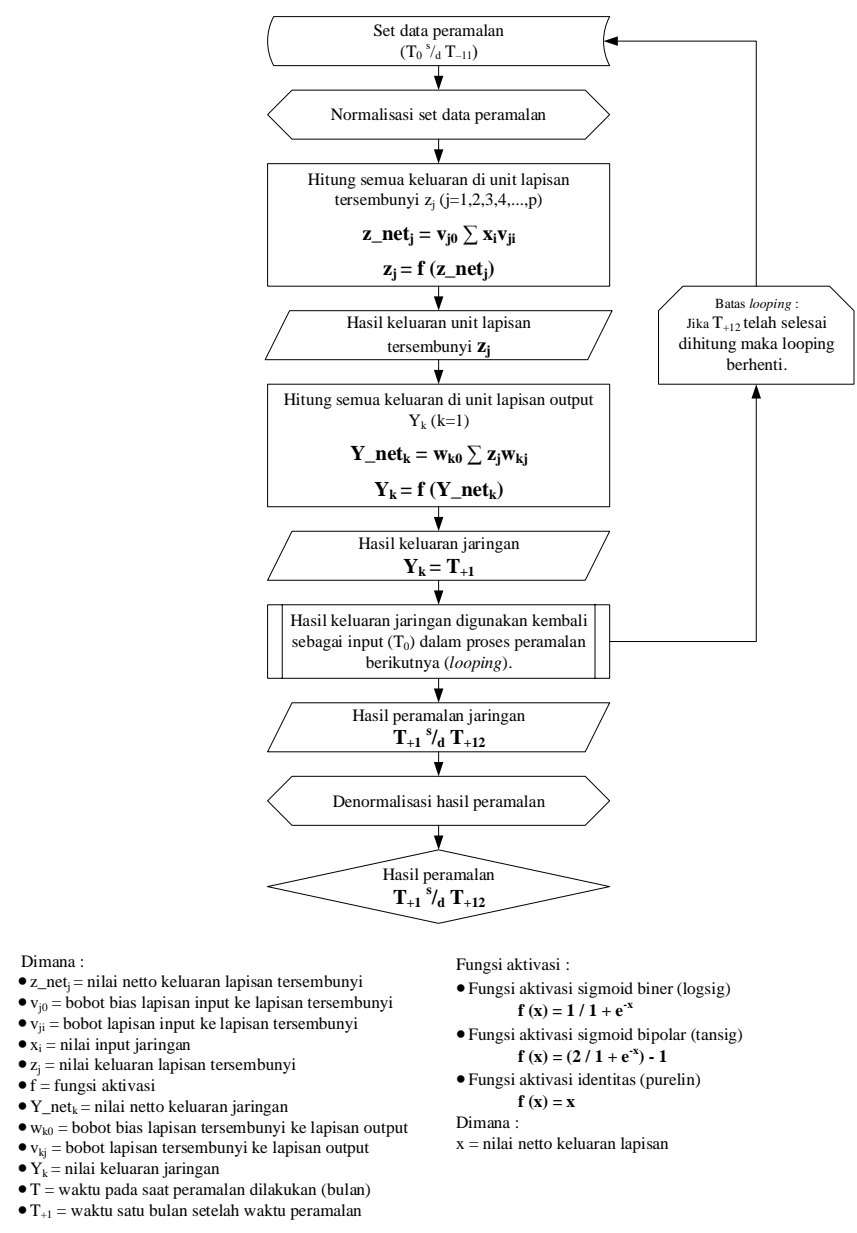

Gambar 6. Algoritma peramalan subsistem proses SPK

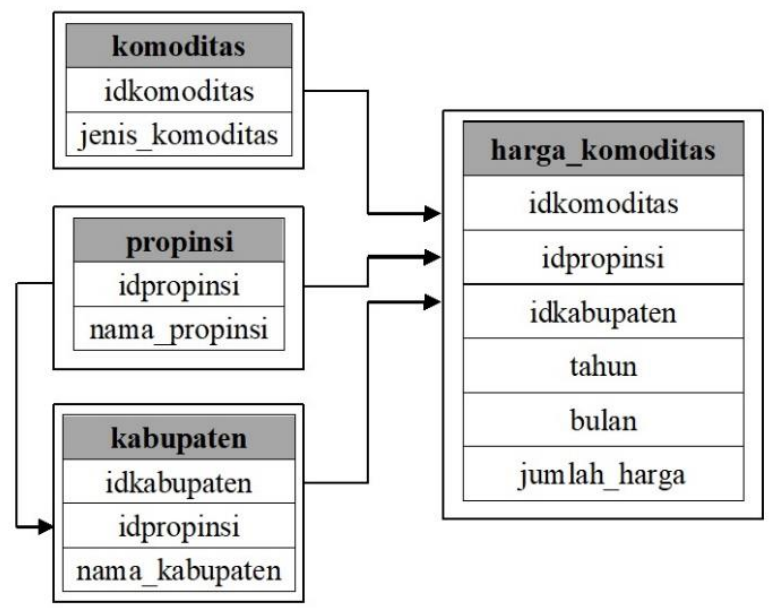

Gambar 7. Subsistem basis data (data base) SPK

\section{Perancangan Subsistem Komponen Pengetahuan (Knowlegde Base)}

Komponen pengetahuan merupakan fitur SPK yang digunakan untuk menganalisa hasil peramalan harga beras yang telah dilakukan oleh subsistem proses (model base) SPK. Perancangan subsistem komponen pengetahuan dilakukan dengan membangun algoritma dukungan keputusan berdasarkan pada matriks keputusan. Subsistem komponen pengetahuan dibangun menggunakan bahasa pemrograman PHP mengikuti algorima dukungan keputusan seperti pada Gambar 8.

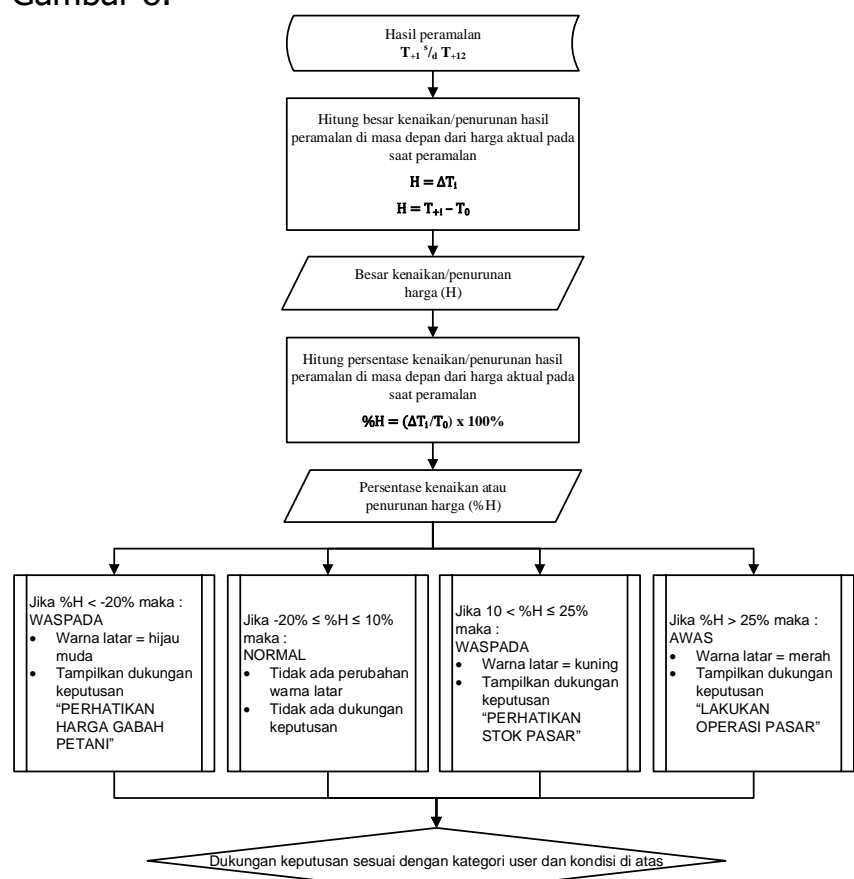

Gambar 8. Algoritma dukungan keputusan subsistem komponen pengetahuan (model base) SPK

\section{Perancangan Subsistem Tampilan Antarmuka (User Interface)}

Perancangan subsistem tampilan antarmuka (user interface) mempertimbangkan keterbatasan kemampuan pengguna terhadap komputer. Oleh karena itu tampilan antarmuka SPK dirancang dengan menggunakan sistem dialog yang mudah digunakan oleh pengguna dengan kemampuan komputer yang minim sekalipun. Tampilan antarmuka dengan sistem dialog dimaksudkan agar SPK dapat menghasilkan output yang sesuai dengan kebutuhan dan permintaan pengguna. Perancangan SPK dan tampilan antarmuka berbasis web (web base) ditujukan untuk: (1) memudahkan pemakaian SPK oleh berbagai instansi yang menjadi sasaran SPK (lintas instansi regulator harga beras); (2) memudahkan pengisian dan pengelolaan basis data (terutama apabila wilayah cakupan SPK diperluas di berbagai provinsi dan kabupaten/kota).

Halaman awal SPK (Home) berisikan penjelasan tentang Sistem Pendukung Keputusan Monitoring dan 
Prediksi Harga Beras Kabupaten Deli Serdang, beserta petunjuk penggunaannya seperti pada Gambar 9.

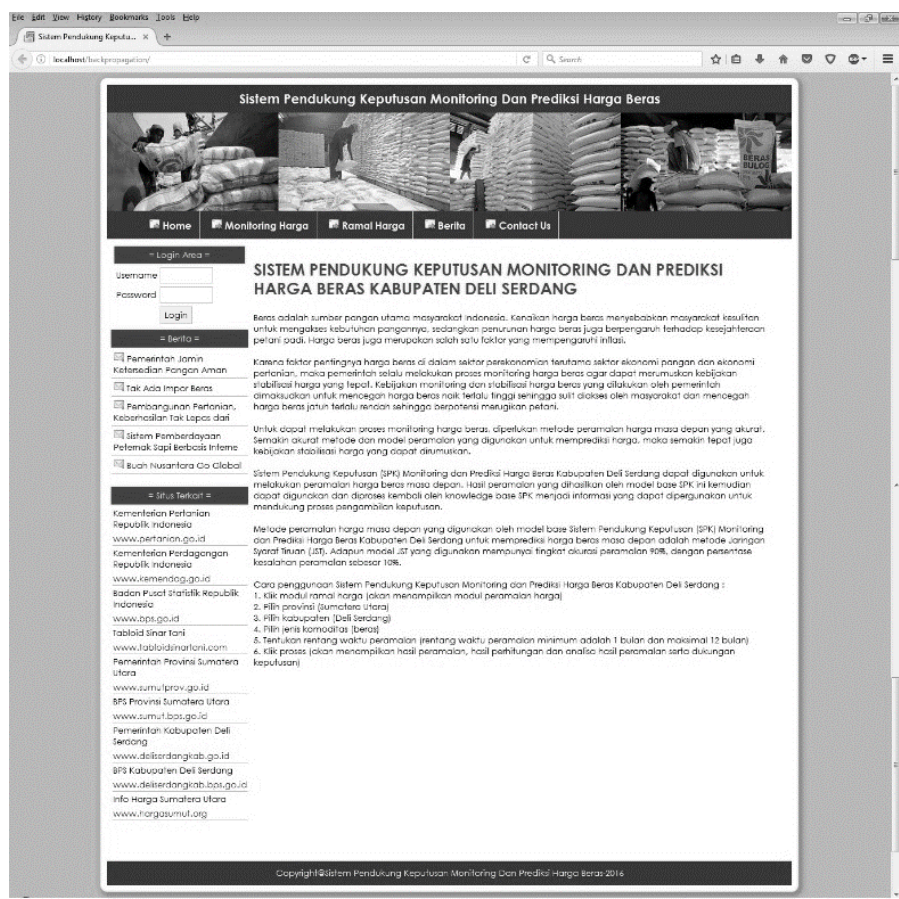

Gambar 9. Tampilan antarmuka halaman index (Home) SPK Monitoring dan Peramalan Harga Beras Kabupaten Deli Serdang

Menu peramalan harga berisikan tampilan dialog berupa combo box yang harus diisi oleh pengguna (user) dengan cara dipilih. Apabila tombol proses diklik oleh pengguna, maka tampilan hasil peramalan akan ditampilkan seperti pada Gambar 10.

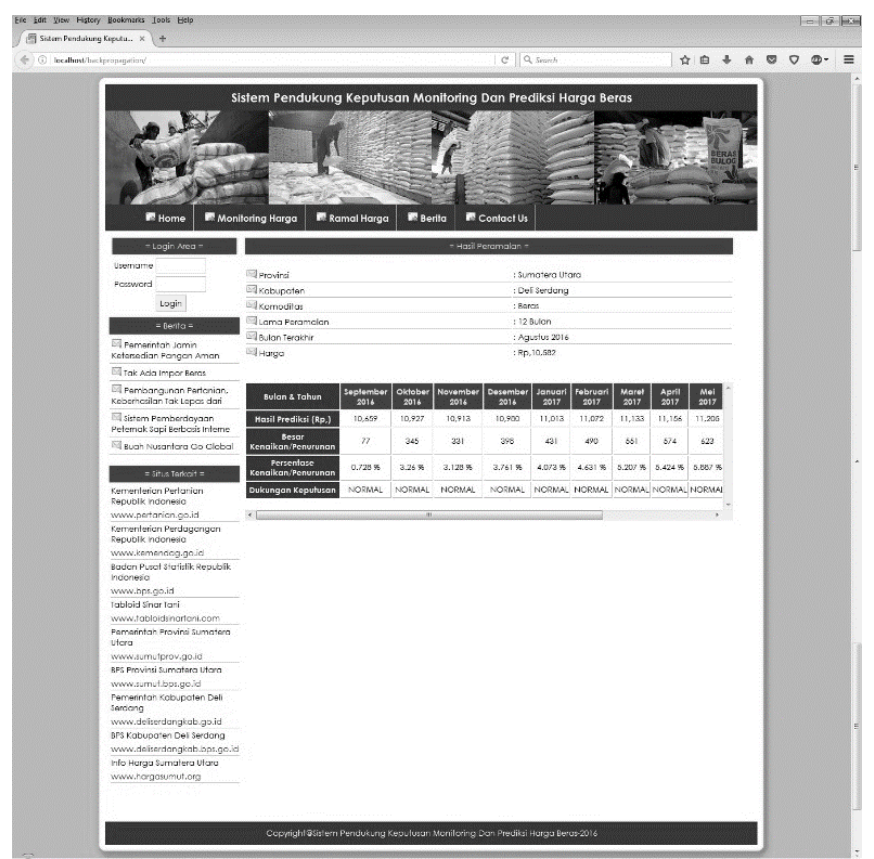

Gambar 10. Tampilan antarmuka halaman hasil Ramal Harga SPK Monitoring dan Peramalan Harga Beras Kabupaten Deli Serdang

Halaman hasil peramalan harga akan menampilkan hasil peramalan harga selama kurun waktu yang telah ditentukan/dipilih oleh pengguna berikut dengan analisa dari hasil peramalan yang telah dilakukan dan dukungan keputusan yang diberikan sebagai tindakan dari hasil analisa yang telah dilakukan oleh SPK terhadap hasil peramalan harga beras.

Menu Monitoring Harga merupakan halaman yang digunakan untuk melihat trend harga beras bulanan di tahun tertentu. Menu Monitoring Harga dijalankan dengan menggunakan data harga beras tingkat bulanan yang tersimpan di dalam basisdata SPK. Menu Monitoring Harga digunakan dengan cara memilih tahun data, kemudian mengklik tombol proses. Setelah proses berjalan, menu Monitoring Harga akan mengeluarkan tampilan seperti Gambar 11.

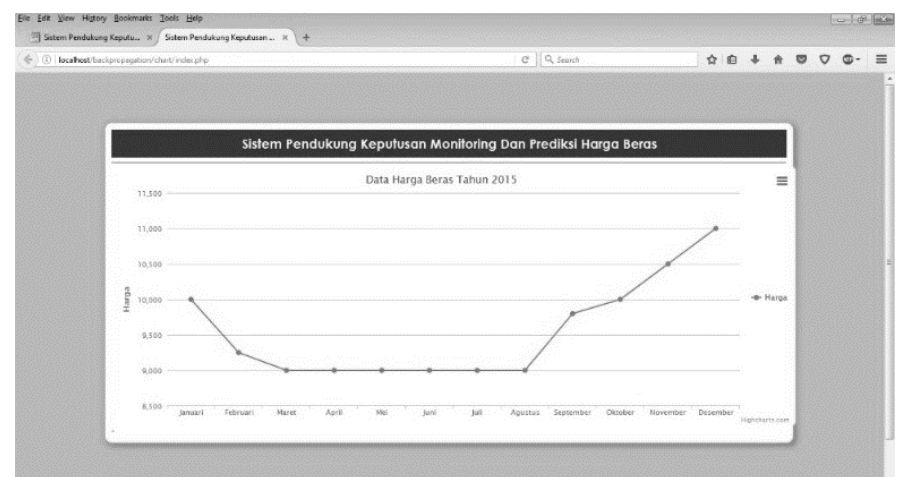

Gambar 11. Tampilan antarmuka hasil Monitoring Harga yang dihasilkan oleh SPK Monitoring dan Peramalan Harga Beras Kabupaten Deli Serdang

\section{KESIMPULAN}

Berdasarkan hasil penelitian, beberapa hal yang dapat disimpulkan adalah (1) Nilai performa pelatihan JST peramalan harga beras terbaik adalah MSE = 0,$00128 ; \quad R=0,7859 ;$ dan MAPE $=5,47 \%$ dan nilai performa pengujian adalah MSE $=0,0319 ; \mathrm{R}=$ 0,90345; dan MAPE $=3,28 \%$. (2) Berdasarkan pada hasil validasi yang telah dilakukan, persentase kesalahan JST peramalan harga beras terbaik yang kemudian dirancang sebagai subsistem proses (model base) SPK adalah kurang dari $10 \%$, dengan tingkat kesalahan peramalan tertinggi sebesar $-6,19 \%$ pada bulan Januari 2015 , dan kesalahan peramalan yang terendah sebesar $-0,07 \%$ pada bulan Februari 2015.

\section{UCAPAN TERIMA KASIH}

Ucapan terima kasih disampaikan kepada Direktorat Jenderal Penguatan Riset dan Pengembangan, Kementerian Riset, Teknologi dan Pendidikan Tinggi Republik Indonesia melalui Program Hibah Penelitian Dosen Pemula 2016.

\section{DAFTAR PUSTAKA}

Candea, C. ., Candea, G. ., \& Filip, F. G. . (2012). IDecisionSupport - A web-based framework for decision support systems. IFAC Proceedings Volumes (IFAC- 
PapersOnline) (Vol. 14). IFAC. https://doi.org/10.3182/20120523-3-RO-2023.00332.

Efendigil, T., Önüt, S., \& Kahraman, C. (2009). A decision support system for demand forecasting with artificial neural networks and neuro-fuzzy models: A comparative analysis. Expert Systems with Applications, 36(3 PART 2), 6697-6707. https://doi.org/10.1016/j.eswa.2008.08.058.

Hamzaçebi, C. (2008). Improving artificial neural networks' performance in seasonal time series forecasting. Information Sciences, 178(23), 4550-4559. https://doi.org/10.1016/j.ins.2008.07.024.

Jakku, E., \& Thorburn, P. J. (2010). A conceptual framework for guiding the participatory development of agricultural decision support systems. Agricultural Systems, 103(9), 675-682. https://doi.org/10.1016/j.agsy.2010.08.007.

Jha, G. K., \& Sinha, K. (2014). Time-delay neural networks for time series prediction: An application to the monthly wholesale price of oilseeds in India. Neural Computing and Applications, 24(3-4), 563-571. https://doi.org/10.1007/s00521-012-1264-z.

Karmakar, S., Laguë, C., Agnew, J., \& Landry, H. (2007). Integrated decision support system (DSS) for manure management: A review and perspective. Computers and Electronics in Agriculture, 572), 190-201. https://doi.org/10.1016/j.compag.2007.03.006.

Khin, A. A. A., F.C, E. C., Shamsudin, M. N., \& Mohamed, Z. A. (2008). Natural rubber price forecasting in the world market. Agriculture Sustainability through Participative Global Extension, 1-13. Retrieved from http://www.fachmannhunter.com/home/wpcontent/uploads/2011/05/aye-eye-khin-66.pdf.

Laboissiere, L. A., Fernandes, R. A. S., \& Lage, G. G. (2015). Maximum and minimum stock price forecasting of Brazilian power distribution companies based on artificial neural networks. Applied Soft Computing, 35, 66-74. https://doi.org/10.1016/j.asoc.2015.06.005.

Leal, I., \& Melin, P. (2007). Time series forecasting of tomato prices in Mexico using modular neural networks and processing in parallel. Studfuzz, 208, 385-402.

Li, G., Xu, S., \& Li, Z. (2010). Short-term price forecasting for agro-products using artificial neural networks. Agriculture and Agricultural Science Procedia, 1, 278-287. https://doi.org/10.1016/j.aaspro.2010.09.035.

Li, Z. min, Cui, L. guo, Xu, S. wei, Weng, L. yun, Dong, X. xia, $\mathrm{Li}, \mathrm{G}$. qiong, \& Yu, H. peng. (2013). Prediction model of weekly retail price for eggs based on chaotic neural network. Journal of Integrative Agriculture, 12(12), 2292-2299. https://doi.org/10.1016/S2095-3119(13)60610-3.

Nainggolan, K. (2007). Perberasan sebagai bagian dari ketahanan pangan nasional. Majalah Agrimedia, 12(2), 110.

Panapakidis, I. P., \& Dagoumas, A. S. (2016). Day-ahead electricity price forecasting via the application of artificial neural network based models. Applied Energy, 172, 132151. https://doi.org/10.1016/j.apenergy.2016.03.089.

Pao, H.-T. (2007). Forecasting electricity market pricing using artificial neural networks. Energy Conversion and Management, 48(3), 907-912. https://doi.org/10.1016/j.enconman.2006.08.016.

Pavan, W., Fraisse, C. W., \& Peres, N. A. (2011). Development of a web-based disease forecasting system for strawberries. Computers and Electronics in Agriculture, 75(1), 169-175. https://doi.org/10.1016/j.compag.2010.10.013.

Rachman, H. P. S. (2005). Metode analisis harga pangan. In Sistem Distribusi Pangan dan Harga Pangan (pp. 78-85).
Bogor: Badan Ketahanan Pangan Republik Indonesia. Retrieved from http://pse.litbang.deptan.go.id/ind/pdffiles/Mono26-7.pdf.

Said, E. G., Bantacut, T., \& Hasbullah, R. (2007). Manajemen rantai pasok beras dan fitur terminal agibisnis biji-bijian. Majalah Agrimedia, 12(2), 35-42.

Simanungkalit, F. J., Sutiarso, L., \& Purwadi, D. (2013). Sistem pendukung keputusan berbasis jaringan syaraf tiruan untuk peramalan harga komoditas tanaman pangan. Agritech, 33(1), 70-80.

Singhal, D., \& Swarup, K. S. (2011). Electricity price forecasting using artificial neural networks. International Journal of Electrical Power \& Energy Systems, 33(3), 550555. https://doi.org/10.1016/j.ijepes.2010.12.009.

Surjasa, D., Sa'id, E. G., Arifin, B., \& Sukardi. (2011). Rancang bangun model prakiraan dan peringatan dini untuk pasokan dan harga beras di Propinsi DKI Jakarta menggunakan jaringan syaraf tiruan. Jurnal Teknik Industri, 1(3), 231-240. 